\title{
Prevalence of Subclinical Keratoconus in Children with Astigmatism in Iraq
}

\author{
Haider Layikh ${ }^{1 *} \mathbb{D}$, Farooq M. Abbas ${ }^{2}$, Hasanain H. Attar ${ }^{1}$, Alyaa A. Kadhum ${ }^{1}$ \\ ${ }^{1}$ Department of Surgery, College of Medicine, Al-Qadisiyah University, Al Diwaniyah, Iraq; ${ }^{2}$ Department of Surgery, Ibn Hayan \\ Medical University, Najaf, Iraq
}

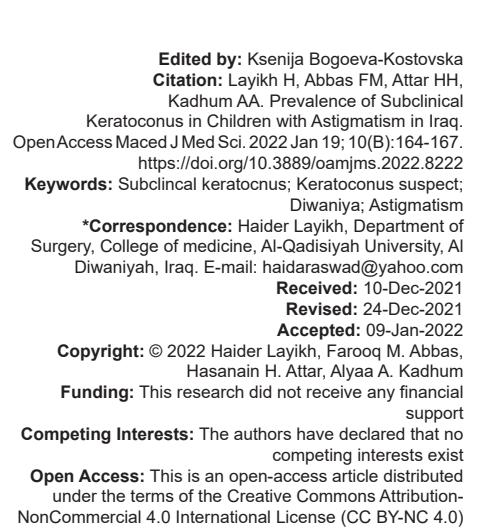

NonCommercial 4.0 International License (CC BY-NC 4.0)

\begin{abstract}
BACKGROUND: Keratoconus is a progressive ectatic corneal pathology that involves both eyes, its usually asymmetrical, its early diagnosis and treatment are vital for the prevention of ocular morbidity that usually happen if it's not treated.

AIM: The study amis to detect the prevalence of subclinical keratoconus and keratoconus suspect in children with astigmatic error of $\geq 2$ Diopters in Diwaniya city, Iraq.

METHODS: This is a cross-sectional, observational study, which investigate all the children aged six to eighteen years with an astigmatic error of $\geq 2$ Diopters who attended the ophthalmology department for a routine eye examination during the period from January 2020 to June 2021. All children underwent full eye examination, and corneal imaging study with modern set which is a pentacam with Scheimpflug technology.

RESULTS: we had 488 children participated in our study, the mean age of participants was $12.01 \pm 1.24$ (range $6-18$ ) years, 255 children were males $(52.2 \%)$, and 233 were female children $(47.7 \%)$ and they were divided into two age groups: first one between 6 and 12 years 225 children (46.1\%), the second one between 12 and 18 years include 263 children (53.8\%). We found 21 children with subclinical keratoconus $(4.3 \%)$ and 24 children were a keratoconus suspects $(4.9 \%)$.

CONCLUSION: The prevalence of keratoconus whether subclinical or suspect among the children with astigmatism who enrolled in our study was relatively high, the use of modern imaging technique tests are vital in the diagnosis.
\end{abstract}

\section{Introduction}

Keratoconus is a progressive ectatic corneal disorder, usually bilateral asymmetrical characterized by progressive astigmatism and myopia of different degrees due to continuous thinning of the cornea which has usually resulted in a progressive visual loss [1].

The etiology of keratoconus not fully understood, but different biomechanical, physical, and genetic factors were blamed resulting in alterations in collagen fiber arrangement of the cornea with progressive protrusion to cone like shape, family history is positive in $8-10 \%$ [2].

Childhood keratoconus is important because of the fast progression rate and late presentation of the patient to eye care centers, usually the child presents with high myopia and astigmatism which affect his social and educational development and his quality of life.

A few pieces of literatures discuss the epidemiology of keratoconus in children, a similar study in Saudi Arabia was conducted and reported an incidence of pediatric keratoconus 4.79\% [3], another study in done by Al-khoory et al. report a relatively low prevalence of $0.53 \%$ in children 14 years old or younger [4].

Vernal keratoconjuctivitis is a chronic allergic, inflammatory disease that involves the conjunctiva usually present with severe itching, redness and discharge, and involvement of the cornea in severe cases, the frequent rubbing of the cornea leads to more release of inflammatory mediators such as interlukinin and protinease which lead to more rubbing and aid in the development and progression of keratoconus [5].

Subclinical keratoconus is defined as a type of keratconus in which the slit lamp and retinoscopic characteristics of the disease were absent, and the diagnosis is challenging, but using the pentacam with Scheimpflug technology aid in the early diagnosis which is very important for early initiation of the treatment plan for the child and avoid complications of late diagnosis [6], [7].

The purpose of our study is to estimate the prevalence of subclinical keratoconus in children with astigmatism $\geq 2 \mathrm{D}$ in Diwaniya city. 


\section{Patients and Methods}

This is a cross-sectional, observational, study that included all the children aged from six to eighteen with an astigmatic error of $\geq 2 \quad D$ who attended the ophthalmology department in Diwaniya teaching hospital for a routine eye examination during the period from January 2020 to June 2021; the study adhered to the tenets of (Helsinki declaration) and it as approved by the ethical committee of Diwaniya medical college of medicine, informed consent was taken from all the child parents discussing the research and its potential benefits for the child and the community.

A detailed history was taken from all the patients include the age of the child, gender, ocular symptoms such as decrease or blurred vision, headache, glare, and monocular diplopia, and symptoms of vernal allergic disease were also recorded; all children with a history of eye surgery or trauma or previously diagnosed with keratoconus were excluded from the study, routine eye examination was done for all patients starting with visual acuity examination using a Snellen chart and the best- corrected visual acuity was recorded after subjective refraction done with autorefractometer and objective one done by retinpscoy after cycloplegic dilatation and the results were recorded for each subject.

Slit-lamp biomicroscopy examination was done also to detect the presence or absence of biomicroscopic signs of Keratoconus such as "progressive thinning, Fleischer's ring, prominent nerves, Vogt's striae, and apical scars."

All subjects, then undergo pentacam imaging study using the pentacam instrument with Scheimpflug technology, it measures the anterior segment of the eye with $3 \mathrm{D}$ examination of the cornea, the examination done with experienced ophthalmologist masked for the child diagnosis, the child was asked for frequent blinding before the test and to focus at center for proper alignment, the image was captured for bot eyes, then realignment of the test done before each capture, and the test considers valid when comment OK appears in the screen.

All test results were examined by two experienced ophthalmologists, all suspected children were reexamined again using biomicroscopy and refraction is done again to be sure it's not a case of keracotonus, if there are no clinical signs for keratoconus; either in K-readings or using retinoscope or by biomicroscopic, the diagnosis of the case whether subclinical Keratocous, Keratocous suspect, and normal was done depending on pentacam tomographer results and examining the tomography maps of patients. If two or more abnormal pentacam features were present like Inferior steepining/atypical bow tie with inferior steepness and I-S ratio over 1.4 , or high posterior elevation or high Keratomtric readings dition to classification (KC) by pentacam software analysis, in absence of any clinical signs of KC; either keratometric, retinoscopic or biomicroscopic), we consider the case as subclinical Keratocous, if one feature present we consider the case as Keratocous suspect.

\section{Results}

There was 488 children who participated in our study, the mean age of participants was $12.01 \pm 1.24$ (range 6-18) years, 255 children were males $(52.2 \%)$ and 233 were a female children $(47.7 \%)$, and they were divided into 2 age groups: first one between 6 and 12 years 225 children (46.1\%) and second one between 12 and 18 years include 263 children (53.8\%).

We found 21 children with subclinical keratoconus (4.3\%) and 24 children were a keratoconus suspects $(4.9 \%)$ and 443 children were normal at the examination, the frequency of disease with percentage and $\mathrm{Cl}$ are shown in Table 1.

Table 1: The classification and frequency of subclinical keratoconus, keratoconus suspects and normal subject

\begin{tabular}{llll}
\hline Classification & Frequency & $\%$ & $\mathrm{Cl}$ \\
\hline Normal subject & 433 & 90.07 & $87.9-92.1$ \\
Keratoconus suspect & 24 & 4.9 & $3.1-5.84$ \\
Subclinical keratoconus & 21 & 4.3 & $2.87-5.27$ \\
\hline
\end{tabular}

We found a significant difference regarding the prevalence of keratoconus suspect among gender ( $p=0.03$ ); it was more common in male patient (15 male 62\%) than female patients (9 female $37 \%$ ), while in cases with subclinical keratoconus, although it is more common in male too, but it is not statistically significant (12 male 57\%) and ( 9 female 43\%) as shown in Table 2.

Table 2: The prevalence of subclinical keratoconus, keratoconus suspect among gender

\begin{tabular}{llllll}
\hline Gender & Disease & Frequency & $\%$ & Cl & p value \\
\hline Male & SKC & 12 & 57 & $2.4-4.1$ & NS \\
& KCS & 15 & 62.3 & $4.23-6.1$ & 0.03 \\
Female & SKC & 9 & 43 & $1.1-4.7$ & NS \\
& KCS & 9 & 37.7 & $3.9-4.2$ & NS \\
\hline \multicolumn{2}{l}{ SKC: Subclinical keratoconus, KCS: Keratoconus suspect, NS: Nonsignificant. }
\end{tabular}

We also found a significant difference among the prevalence of both sub clinical keratoconus and keratoconus susupect in the older age group (12-18 years) than younger age group (6-12 years) where $(p<0.001)$, as shown in Table 3.

Table 3: The prevalence of subclinical keratoconus, keratoconus suspect among different age groups

\begin{tabular}{llllll}
\hline Age group & Disease & Frequency & $\%$ & $\mathrm{Cl}$ & $\mathrm{p}$ value \\
\hline 6-12 year & SKC & 6 & 28.6 & $1.02-3.2$ & $<0.001$ \\
& KCS & 7 & 29.1 & $2.9-4.1$ & $<0.001$ \\
$12-18$ year & SKC & 15 & 71.4 & $3.2-5.2$ & $<0.001$ \\
& KCS & 17 & $70.08 \%$ & $4.3-6.1$ & $<0.001$ \\
\hline "SKC: Subclinical keratoconus, KCS: Keratoconus suspect.
\end{tabular}




\section{Discussion}

This study aimed to determine the prevalence of subclinical keratoconus and suspected keratoconus in the child and adolescent age group (6-18) in Diwaniya region in Iraq which was $4.3 \%, 4.9 \%$, respectively, using the modern corneal imaging technique with Scheimpflug technology besides clinical examination by an expert ophthalmologist; the result was higher than previous reports on keratoconus prevalence [8], [9], [10], [11], [12], [13], [14], [15], [16], [17].

The first landmark article on keratoconus prevalence was published by Kennedy et al. [4] on 1986, the result based on examination by retinoscopy technique to detect irregular scissoring reflex of the cornea of patients with keratconus over a span of 48 years on the population of Minnesota, USA. The overall prevalenve was $0.05 \%$ only, and it remained the most cited article in this subject till now, since the introduction of more advanced examination technique the ratio increase; similar study done in our area with the comparable result was done by Torres et al. [3] in Saudi Arabia with a prevalence rate of $4.79 \%$ among children under 21 years old; however, they depend only on modern examination by imaging tomography not a clinical examination and they don't differentiate suspected from subclinical cases of keratconus like in our study.

Another recent study from Netherland [18] show an increase incidence of keratoconus in the general population to be $0.23 \%$ depending on analyzing reocrds from the insurance health system in contrast to our study which depends on clinical examination and corneal imaging study also to increase the detected subjects and made the ratio increase.

The prevalence of keratoconus is varied among areas and populations; it might be due to genetics, ethnic, diagnostic, and environmental reasons [9], [12], [14], [18], [19]; in 2000, Pearson et al. [15] suggested ethnic variations in the prevalence of keratoconus for the first time, in their study, a fourfold increase in the prevalence among Asian people $(0.26 \%)$ than Caucasian $(0.05 \%)$ however a lot of pieces literatures [9], [12], [18], [19].

Itshowsanincreased prevalence of keratoconus among people in the middle east region which might be due to ethnic cause or it related to increasing incidence of allergic disorders and spring catarrh., in our study $(27 \%)$ of our patient with keratoconus has a positive history and examination for VKH which higher than in the other subjects $(8.3 \%)$ which might report a relation between frequent eye rubbing in early childhood and the development of keratoconus which is not proved till now and need more investigations.

Our study shows an increased prevalence of keratoconus among male subjects, similar study show also increase prevalence in male compared to female [15], while other studies show that female has more prevalence rate [20], [21] and other researchers found no gender diffreneces [8], [20].

Furthermore, in our research, we divide the research population into two age groups to focus on the increased prevalence among older children who will be advised to undergo screening programs for keratoconus more frequently than younger kids; the prevalence was much higher in the older age group and its statistically significant, similar study done by Awwad et al. [22] show the same high prevalence among the older children.

Our study has some limitations to acknowledge; it's a cross-section study, while a cohort type of research study be more informative about the nature of the disease and its progression, also we use a clinical-based sample, not a population-based sample which would be better in assessing a prevalence of a disease, although the high prevalence rate among those kids who attend the ophthalmology department with astigmatism in Diwaniya city will raise a flag to start adequate population-based research and cooperate the results of this study [23].

Another limitation of every study using a human interface to assess the clinical outcome; there was some discrepancy between our examiners about some query cases, and we judged the tomography results to be the final decision.

Keratoconus in a child is more aggressive and fast progress than adult; this might be due to structural liability of collagen fibers in child cornea, so early diagnosis is vital with proper selection of treatment plan to prevent deterioration and ocular morbidity.

\section{Conclusion}

Keratoconus is a serious disease especially in children, so early detection is important to pervert complications, introduction of modern imaging study is vital to achieving this goal.

The prevalence of this disease among children with astigmatism is high which might need a schoolbased screening program for early detection.

\section{References}

1. Mukhtar S, Ambati BK. Pediatric keratoconus: A review of the literature. Int Ophthalmol. 2018;38(5):2257-2266. https://doi. org/10.1007/s10792-017-0699-8

PMid:28852910 
2. Mas Tur V, MacGregor C, Jayaswal R, O'Brart D, Maycock N. A review of keratoconus: Diagnosis, pathophysiology, and genetics. Surv Ophthalmol. 2017;62(6):770-783. https://doi. org/10.1016/j.survophthal.2017.06.009

\section{PMid:28688894}

3. Torres Netto EA, Al-Otaibi WM, Hafezi NL, Kling $\mathrm{S}$, Al-Farhan HM, Randleman JB, et al. Prevalence of keratoconus in paediatric patients in Riyadh, Saudi Arabia. Br J Ophthalmol. 2018;102(10):1436-41. https://doi.org/10.1136/ bjophthalmol-2017-311391

PMid:29298777

4. El-Khoury S, Abdelmassih Y, Hamade A, Slim E, Cherfan CG, Chelala $\mathrm{E}$, et al. Pediatric keratoconus in a tertiary referral center: Incidence, presentation, risk factors, and treatment. J Refract Surg. 2016;32(8):534-541. https://doi.org/10.3928/10 81597X-20160513-01

PMid:27505314

5. Balasubramanian SA, Pye DC, Willcox MD. Effects of eye rubbing on the levels of protease, protease activity and cytokines in tears: Relevance in keratoconus. Clin Exp Optom. 2013;96(2):214-8. https://doi.org/10.1111/cxo.12038 PMid:23496656

6. de Sanctis U, Loiacono C, Richiardi L, Turco D, Mutani B, Grignolo FM. Sensitivity and specificity of posterior corneal elevation measured by Pentacam in discriminating keratoconus/ subclinical keratoconus. Ophthalmology. 2008;115(9):1534-9. https://doi.org/10.1016/j.ophtha.2008.02.020

PMid: 18405974

7. de Sanctis U, Missolungi A, Mutani B, Richiardi L, Grignolo FM. Reproducibility and repeatability of central corneal thickness measurement in keratoconus using the rotating Scheimpflug camera and ultrasound pachymetry. Am J Ophthalmol. 2007;144(5):712-8. https://doi.org/10.1016/j.ajo.2007.07.021 PMid: 17869208

8. Waked N, Fayad AM, Fadlallah A, El Rami H. Dépistage du kératocône dans une population universitaire au Liban [Keratoconus screening in a Lebanese students' population]. J Fr Ophthalmol. 2012;35(1):23-29. https://doi.org/10.1016/j. jfo.2011.03.016

PMid:21715046

9. Millodot M, Shneor E, Albou S, Atlani E, Gordon-Shaag A. Prevalence and associated factors of keratoconus in Jerusalem: A cross-sectional study. Ophthalmic Epidemiol. 2011;18(2):91-7. https://doi.org/10.3109/09286586.2011.560747 PMid:21401417

10. Waked N, Fayad AM, Fadlallah A, El Rami H. Keratoconus screening in a Lebanesestudents' population. J Fr Ophtalmol 2012;35(1):23-9. https://doi.org/10.1016/j.jfo.2011.03.016 PMid:21715046

11. Hashemi $H$, Beiranvand $A$, Khabazkhoob $M$, Asgari $S$, Emamian $\mathrm{MH}$, Shariati M, et al. Prevalence of keratoconus in a population-basedstudyinShahroud. Cornea.2013;32(11):1441-5. https://doi.org/10.1097/ICO.0b013e3182a0d014 PMid:24042484

12. Hashemi $\mathrm{H}$, Khabazkhoob M, Yazdani N, Ostadimoghaddam $\mathrm{H}$, Norouzirad R, Amanzadeh K, et al. The prevalence of keratoconus in a young population in Mashhad, Iran. Ophthalmic Physiol Opt. 2014;34(5):519-27. https://doi.org/10.1111/opo.12147 PMid:25131846

13. Shneor E, Millodot M, Gordon-Shaag A, Essa M, Anton M, Barbara R, et al. Prevalence of keratoconus among Young Arab students in Israel. Int J Keratoconus Ectatic Corneal Dis 2014;3:9-14.

14. Shehadeh MM, Diakonis VF, Jalil SA, Younis R, Qadoumi J, Al-Labadi L. Prevalence of keratoconus among a palestinian tertiary student population. Open Ophthalmol J. 2015;9:172-6. https://doi.org/10.2174/1874364101509010172 PMid:26962381

15. Pearson AR, Soneji B, Sarvananthan N, Sandford-Smith JH. Does ethnic origin influence the incidence or severity of keratoconus? Eye. 2000;14(Pt 4):625-8. https://doi.org/10.1038/ eye.2000.154

PMid:11040911

16. Jonas JB, Nangia $V$, Matin A, Kulkarni M, Bhojwani $K$ Prevalence and associations of keratoconus in rural maharashtra in central India: The central India eye and medical study. Am JOphthalmol. 2009;148(5):760-5. https:// doi.org/10.1016/j.ajo.2009.06.024

PMid:19674732

17. Xu L, Wang YX, Guo Y, You QS, Jonas JB, Beijing Eye Study Group. Prevalence and associations of steep cornea/ keratoconus in Greater Beijing. The Beijing Eye Study. PLoS One. 2012;7(7):e39313. https://doi.org/10.1371/journal.pone.0039313 PMid:22792169

18. Godefrooij DA, de Wit GA, Uiterwaal CS, Imhof SM, Wisse RP. Age-specific incidence and prevalence of keratoconus: A nationwide registration study. Am J Ophthalmol 2017:175:169-72.

19. Hashemi H, Khabazkhoob M, Fotouhi A. Topographic keratoconus is not rare in an iranian population: The Tehran eye study. Ophthalmic Epidemiol. 2013;20(6):385-91. https://doi.org /10.3109/09286586.2013.848458

PMid:24168025

20. Elbedewy HA, Wasfy TE, Soliman SS, Sabry MM, Awara A, EI Emam SY, et al. Prevalence and topographical characteristics of keratoconus in patients with refractive errors in the Egyptian delta. Int Ophthalmol. 2019;39(7):1459-65. https://doi. org/10.1007/s10792-018-0965-4 PMid:29938312

21. Krachmer JH, Feder RS, Belin MW. Keratoconus and related noninflammatory corneal thinning disorders. Surv Ophthalmol 1984;28:293-322. https://doi.org/10.1016/0039-6257(84)90094-8 PMid:6230745

22. Gokhale NS. Epidemiology of keratoconus. Indian J Ophthalmol. 2013;61:382-3. https://doi.org/10.4103/0301-4738.116054 PMid:23925318

23. Awwad ST, Yehia M, Mehanna CJ, Abdul Fattah M, Saad A Hatoum A, et al. Tomographic and refractive characteristics of pediatric first-degree relatives of keratoconuspatients. Am J Ophthalmol. 2019;207:71-6. https://doi.org/10.1016/j. ajo.2019.05.032

PMid:31194951 